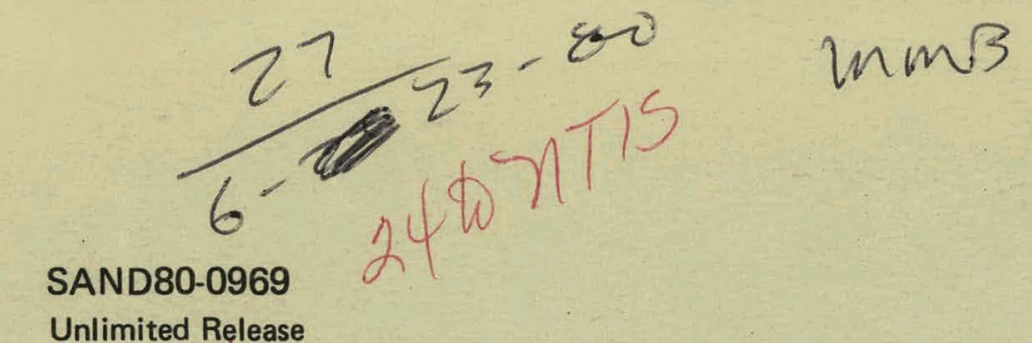

Unlimited Release UC-13 38

\title{
Sandia LSI Accelerated Aging and Data Acquisition Techniques
}

James E. Walker

Prepared by Sandia Laboratories, Albuquerque, New Mexico 87185 and Livermore, California 94550 for the United States Department of Energy under Contract DE-AC04-76DP00789

Printed May 1980 


\section{DISCLAIMER}

This report was prepared as an account of work sponsored by an agency of the United States Government. Neither the United States Government nor any agency Thereof, nor any of their employees, makes any warranty, express or implied, or assumes any legal liability or responsibility for the accuracy, completeness, or usefulness of any information, apparatus, product, or process disclosed, or represents that its use would not infringe privately owned rights. Reference herein to any specific commercial product, process, or service by trade name, trademark, manufacturer, or otherwise does not necessarily constitute or imply its endorsement, recommendation, or favoring by the United States Government or any agency thereof. The views and opinions of authors expressed herein do not necessarily state or reflect those of the United States Government or any agency thereof. 


\section{DISCLAIMER}

Portions of this document may be illegible in electronic image products. Images are produced from the best available original document. 
Issued by Sandia Laboratories, operated for the United States Department of Energy by Sandia Corporation.

\section{NOTICE}

This report was prepared as an account of work sponsored by the United States Government. Neither the United States nor the Department of Energy, nor any of their employees, nor any of their contractors, subcontractors, or their employees, makes any warranty, express or implied, or assumes any legal liability or responsibility for the accuracy, completeness or usefulness of any information, apparatus, product or process disclosed, or represents that its use would not infringe privately owned rights.

SF $1004-D F(11-77)$ 
SAND8 0-0969

Unlimited Release

Printed May 1980

SANDIA

LSI ACCELERATED AGING

AND

DATA ACQUISITION

TECHNIQUES

Electronic \& Electrical Devices Division

Sandia National Laboratories

Albuquerque, New Mexico 87185

Aprii 1980

ABSTRACT

Accelerated aging studies on the LSI technology are performed in the Sandia Microelectronics Evaluation Lab. Reliability and life distributions are estimated from failure rate measurements. 
TABLE OF CONTENTS

Section

$\underline{\text { Page }}$

LIST OF ILLUSTRATIONS .......................... 3

1. INTRODUCTION ............................... 4

1.1 History............................ 4

1.2 Purpose of the Microelectronic Evaluation Lab...... 4

1.3 Definition of Accelerated Aging............... 5

1.4 Device Types............................. 6

2. TECHNIQUES OF ACCELERATEd AGING................. 7

2.1 Screening and PDA Requirements................ 7

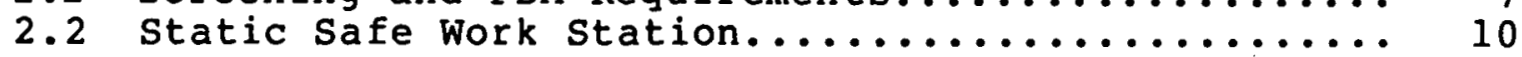

2.3 Device Packages.......................... 12

2.4 Device Burn-In (Accelerated Aging)............. 14

2.4.1 Preparation of Devices at Static-Safe Work

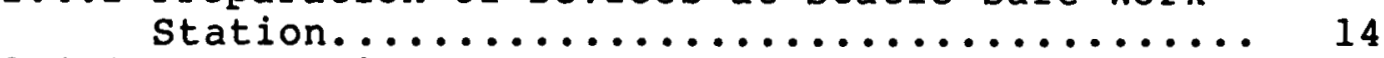

2.4.2 Preparation of Burn-In Boards............. 14

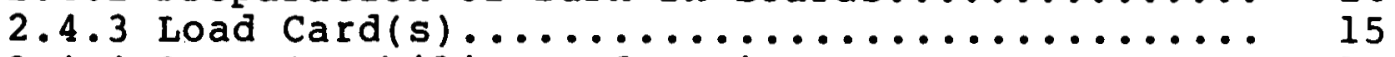

2.4 .4 Oven Capability and Device Burn-In......... 15

2.4.5 Unloading and Preparation for Device Testing 21

3. DEVICE TESTING............................ 23

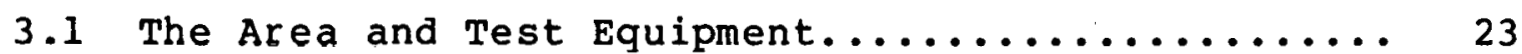

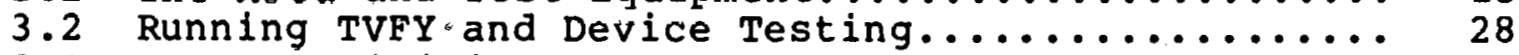

3.3 Data Acquisition............................ 29

4. THE USE OF FAILURES......................... 30

5. SUMMARY AND CONCLUSIONS....................... 30

6. REEERENCES ............................... 33 


\section{LIST OF ILLUSTRATIONS}

Figure

Page

1. Failure Rate Versus Life Curve.................. 8

2. Flow Diagram of Device Electrical Screening......... 9

3. Static-Safe work station..................... 11

4. Typical Devices, Sockets, Carriers and Clips........, 13

5a. Burn-In Oven systems....................... 17

5b. Front, close-Up view of an Oven System............ 18

5c. Back, Close-Up View of an Oven system.............. 19

6. Apparatus for Transporting Static Sensitive Devices... 22

7. Test Area and Equipment.................... 25

8. Interface Units and Performance Boards............ 26

9. Flow Diagram of Accelerated Aging Burn-In, Test and Failure Analysis Cycle....................... 31 


\section{SECTION I}

\section{INTRODUCTION}

\subsection{History}

The Microelectronics Evaluation Laboratory (MEL) was created in April, 1976, in response to a request by Sandia engineering. The purpose was to develop an evaluation program for CMOS LSI technology devices which were being used for the first time in a weapon system. The objectives of this evaluation program are, 1) to determine that the LSI devices will perform their intended functions during stockpile life, 2) to determine functional life and time-to-failure distributions, 3) to identify unpredicted failure modes, and 4) to provide baseline life test data for future evaluations. The objectives are accomplished through the use of accelerated aging techniques. These techniques are the main subject of this report.

\subsection{Purpose of the Microelectronic Evaluation Lab}

The main operations performed in the MEL are accelerated aging studies and electrical tests to determine the stockpile life and reliability of a device. The ever increasing complexity of microcircuits and the sophistication of military and space equipment using microcircuits demand a significant improvement in the state-of-the-art for qualification of microcircuit de- 
signs and suppliers, and for defect screening. Because of this, a commitment was made to use devices with "high" reliability, where high reliability is defined as a high probability that a randomly selected device from a group of devices will function throughout its in-system life without failure. High temperature burn-in and life testing, sometimes called high-temperature operating-test (НTOT), provide dramatic improvement in microcircuit reliability and reduce test time and cost.

\subsection{Definition of Accelerated Aging}

Accelerated aging is a burn-in operation under conditions using one or more applied stimuli which may or may not exceed the maximum rated operating or storage stress levels. The stresses used are temperature and voltage. Burn-in is the process of storing a device at elevated temperature with or without a voltage stimulus applied. With no voltage stimulus applied and with temperatures above $25^{\circ} \mathrm{C}$, the burn-in process is called "stabilizationbake" or "bake-out;" with no stimulus applied and with temperatures below $25^{\circ} \mathrm{C}$ the process is called "stabilization-cool."

Aging data have shown IC life distributions to be composed of three regions: infant mortality, "freaks," and main life. Infant mortality results from a variety of failure mechanisms due to manufacturing defects of a mechanical nature, e.g., open bonds, cracked chips, defective die bonds, gross mask defects, etc. Freaks result 
from some extreme combination of effects in individual devices where failure mechanisms show up at earlier times than would be predicted from the time-to-failure distribution of the main failure mechanism. Main life failures are thought to be due to one failure mechanism having a single activation energy ( $E_{\dot{A}}$ ), where $E_{A}$ is a measure of the relationship between temperature and time for failure mechanisms in IC's. The relationship of $E_{A}$ for IC failures to the semiconductor physics definition of such features as barrier or quantum energy levels (l.11ev for silicon at $27^{\circ} \mathrm{C}$ ) is not definite except for specific cases such as the energy required to form or break a chemical bond. The ideal effect of burn-in is the removal of all infant mortality and freak failures. The remaining devices will then be entirely in the main ifife category and accurate reliability predictions can be made.

\subsection{Device Types}

Devices which come to the MEL for microcircuit evaluation are usually constructed with materials capable of withstanding longterm, electrically biased operation at temperatures up to $300^{\circ} \mathrm{C}$. Careful selection of the electrical and thermal stress mechanisms without introducing damaging or unrealistic failure is essential for maximum acceleration of use-condition failure modes. AlI device materials including the package, lead finish, die attachment, and package seal are involved. All processes (bipolar, MOS, CMOS, NMOS, etc.) and circuit applications, (digital or linear) can be 1 ife-tested. 


\section{SECTION 2}

\section{TECHNIQUES OF ACCELERATED AGING}

\subsection{Screening and PDA Requirements}

The MEL receives devices from organizations such as RCA, Fairchild, Signetics, and the Sandia Semiconductor Development Laboratory (SDL). Regardless of the source of the devices, each part goes through a "screening" process which is usually performed by the manufacturer. Through screening, all "infant mortality" devices should be removed. The term "screening" is used here to describe the application of some test to 1008 of the product in order to remove defective or potentially defective units, i.e., the infant mortality. Electrical parametric or functional testing is a screen and, in some cases, can be aimed at reliability failures (future) as well as immediate defects. The attention in the MEL is given mostly to accelerated testing of microcircuits, involving temperature and/or voltage. At the start of an aging study, however, attention is focused on the burn-in function of screening. Before a device sample is placed in accelerated aging, screening must pass the PDA (percent defective allowed) as described in MILSTD-883B. Under PDA, a group of devices is accepted if the percent defective is less than a specified value (58), rejected if it is greater than a specified value (15\%), or returned to burn-in if between these values. Excluding the preburn-in electrical tests, the devices are normally limited to two burn-ins, after which they 
are rejected or accepted using the same criteria. The pre-burnin test verifies that all devices received from suppliers are functional. Figure 1, Part $I$, indicates the change in failure rate due to infant mortality during screening. Figure 2 shows a flow diagram of the burn-in process of screening for a typical PDA requirement.

In accelerated aging, the object is to determine the useful life and wear-out period of a device. These are shown as Parts II and II of Figure 1. The slightly decreasing failure rate in the normal life of the curve is due to freak failures. With a constant failure rate in Part II, all freaks would have been removed during the infant mortality period.

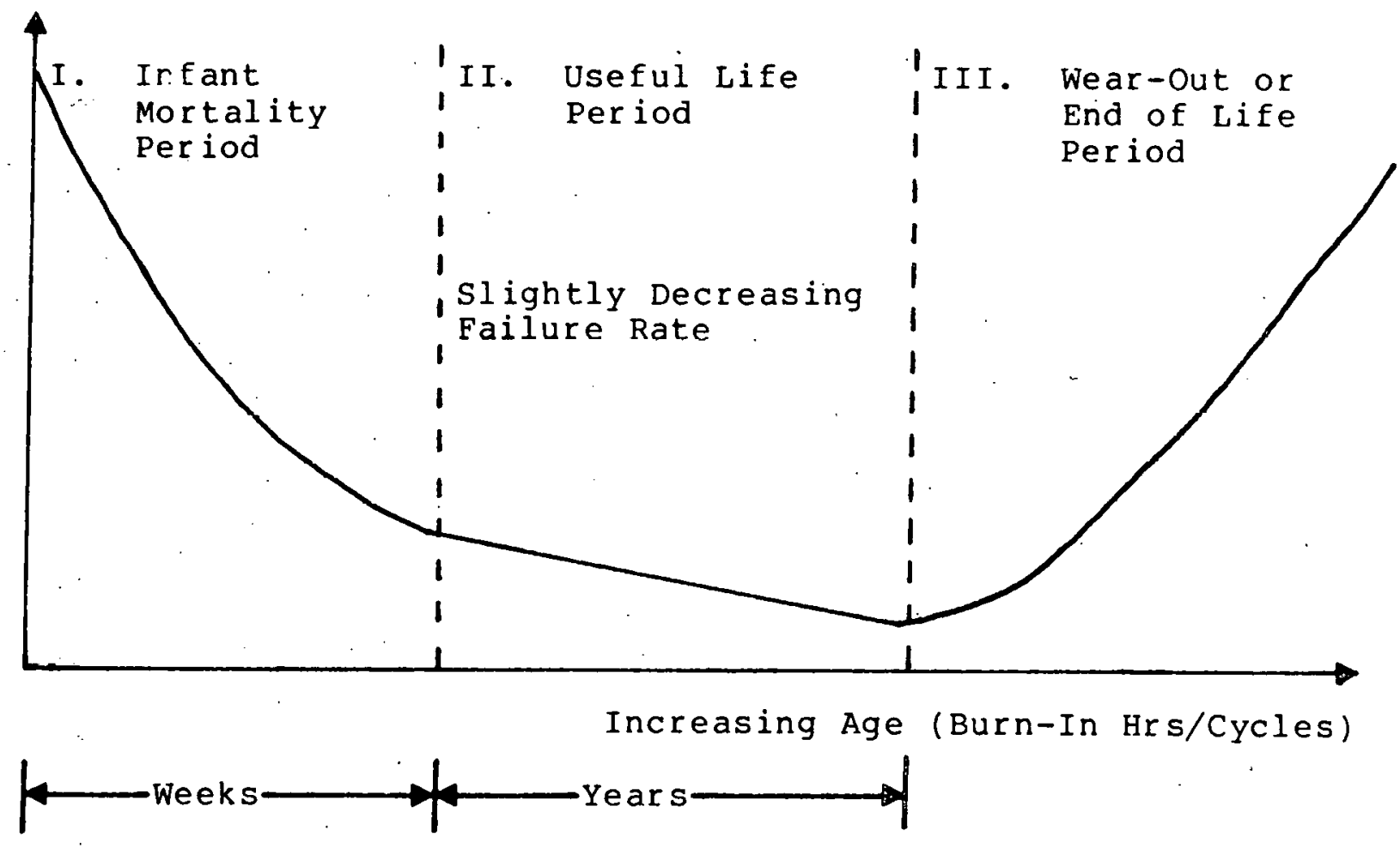

Figure 1 - Failure Rate Versus Life curve 


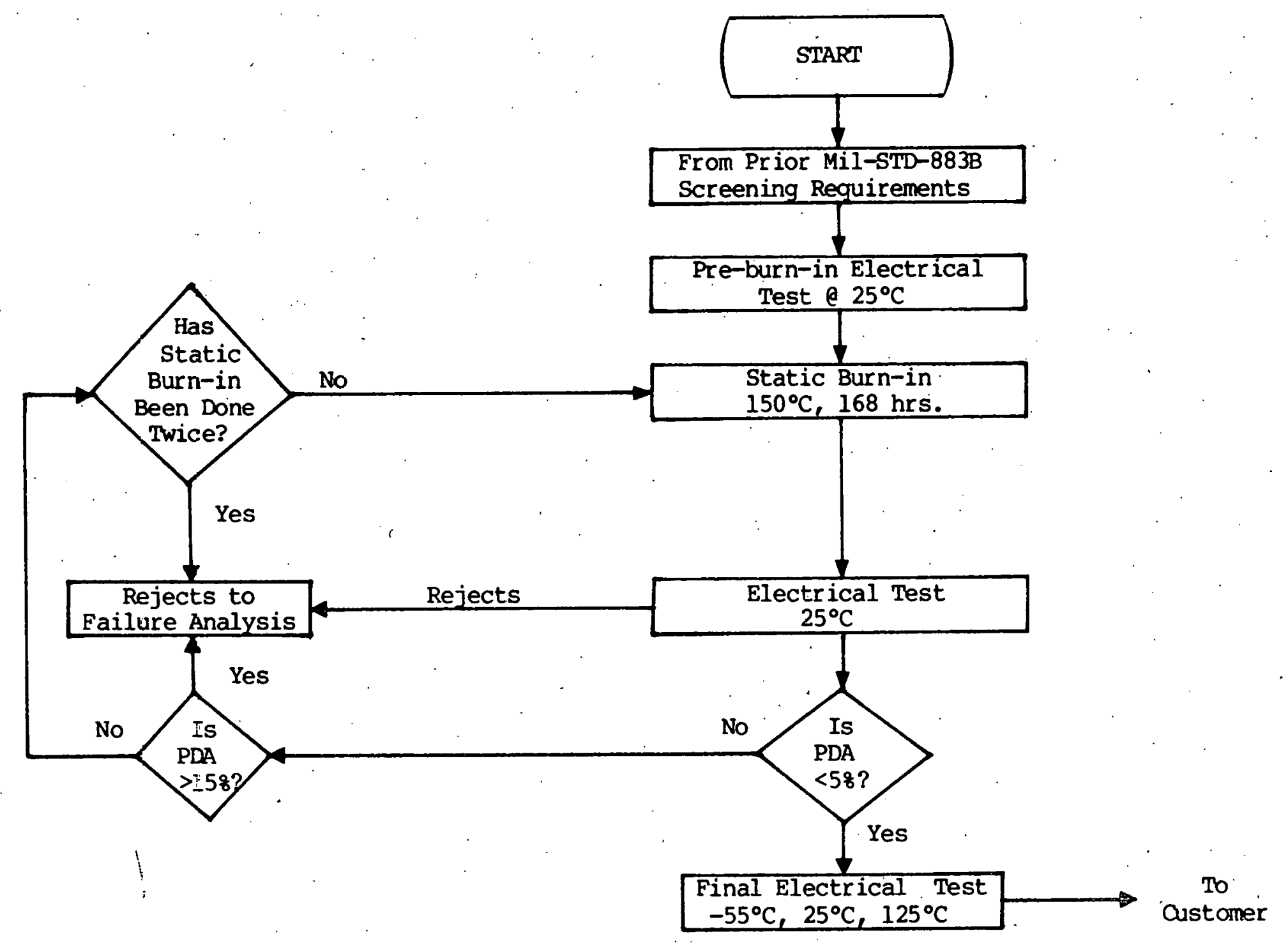

Figure 2 - Flow Diagram of Device Electrical Screening 


\subsection{Static-Safe Work Station}

The accelerated aging process involves burn-in boards, sockets, carriers, a work station and the necessary tools and equipment for controlling static discharge. Shown in Figure 3 is a typical "static-safe" work station. The definitions 1 isted below describe the various elements.

1. Static-Safe Floor Mat - Drains away static charges which ordinary carpets or floors generate.

2. Static-Safe Bench Top - Continually drains static charges to ground. Any item on this surface is grounded.

3. Static Ground Cord - Completes path to ground between conductive bench top and floor mat.

4. Ionized Air Blower - Bathes working areas with ionized air. Static can be neutralized on nonconductors such as nylon garments and common plastic trays.

5. Static-Safe Container - Shields parts from electrostatic fields during transporting and continually aids dissipation of static.

6. Static-Safe Bag - Protects parts from electrostatic fields and offers physical protection as well. Unlike anti-static plastic bags, static-safe bags require no humidity to be effectively volume conductive. Most conductive bags are effective even at zero humidity levels and are not affected by age.

7. Conductive Foam - Protects parts from physical shock as well as static electrical discharge.

8. Conductive pockets - offer the sane protection as conductive foam except that the specially made pockets are primarily used with Leadless Hermetic Package type devices.

9. Accelerated Aging Burn-in Board - Supplies bias to devices during burn-in with the aid of the device sockets and burn-in circuitry as seen on the face of the board. 


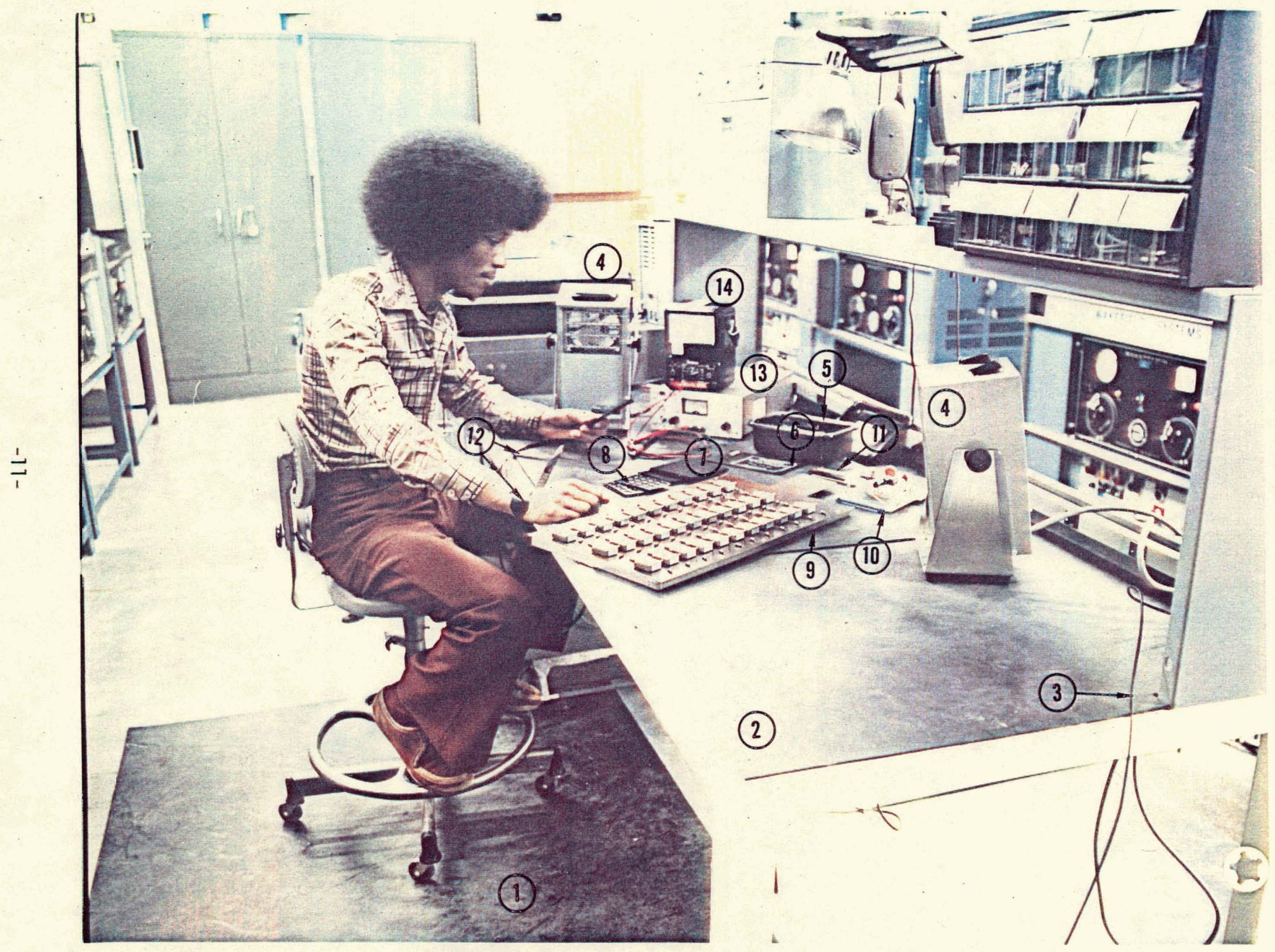

FIGURE 3 - Static-Safe Work Station 
10. Load Card - Supplies bias to burn-in board during burn-in.

11. Shorted Edge Connector - Eliminates static charges during transport of burn-in board from static bench top to oven. It consists of a shorting strip placed on the top edge end of a device-loaded burn-in board.

12. Wrist Strap - Removes static charges from personnel and drains them to ground.

13. Power Supply - Supplies bias to the burn-in board through the load card to simulate bias conditions during burn-in.

14. VOM - Volt-ohm meter used to check burn-in boards for correct operation.

\subsection{Device Packages}

So far four device package types have been tested in the MEL: the two-sided and four-sided flat pack, the leadless hermetic package and the dual-in-line package. Figure 4 shows typical devices with their appropriate socket, carrier and clip to show how each is mounted. In row 1 of Figure 4 is a four-sided flat pack device, in row 2 is a two-sided flat pack device, in row 3 is a leadless device and in row 4 is a dual-in-line device. Each of the devices is mounted to its carrier and socket as shown from right to left. Considering the steps for loading a device into a socket were numbered from 1 to 5 ( $r$ ight to left) in each row, Column 1 contains the "clips," Column 2 contains the devices, Column 3 contains the carrier, Column 4 shows the packaged device as it will be inserted into the socket (except the two-sided flat pack which should be rotated $180^{\circ}$ ), and Column 5 contains the sockets. Note that only flat pack devices use carriers and clips. Socket mounting on burn-in boards was shown in Figure 3 . 

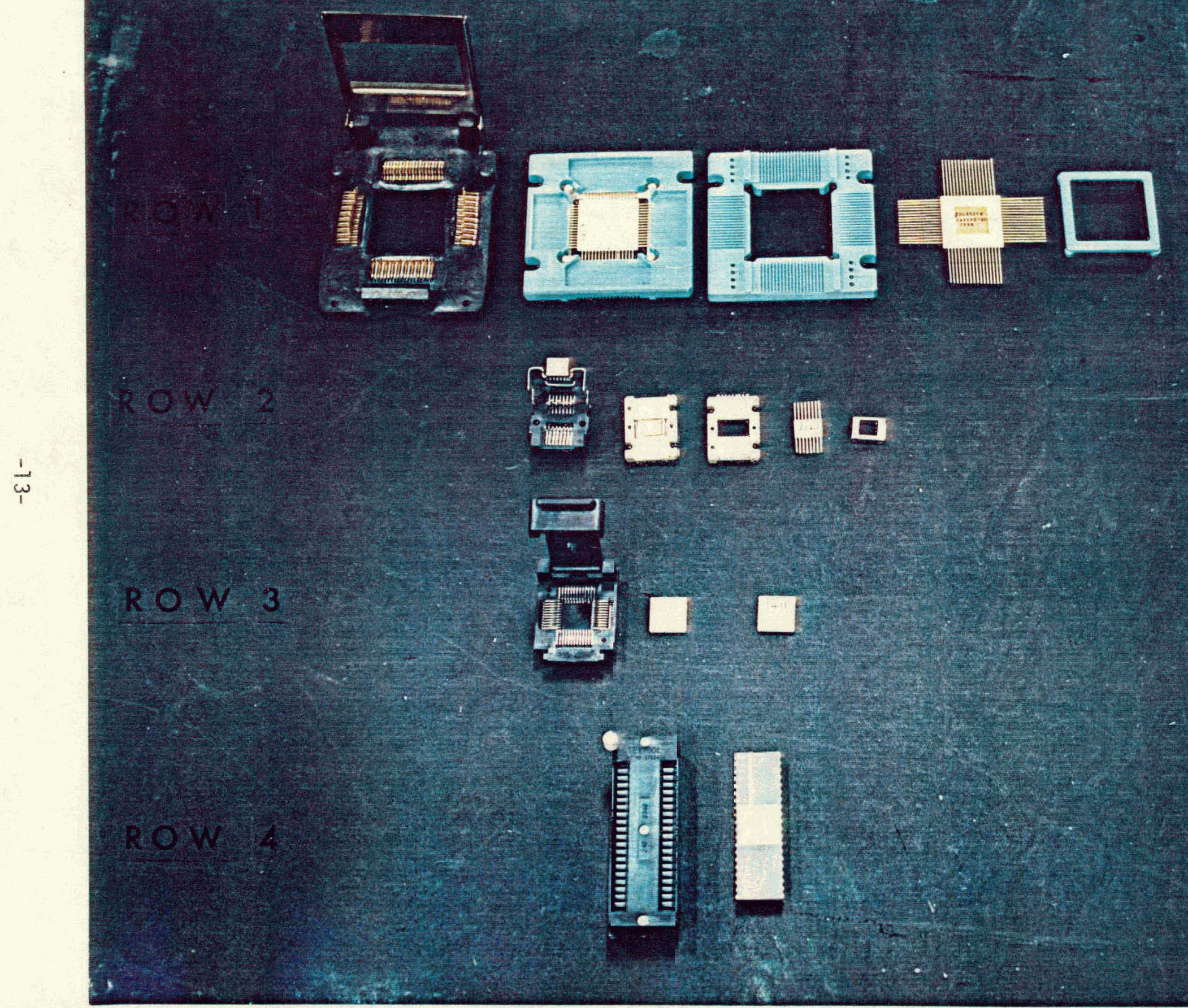

FIGURE 4 - Typical Devices, Sockets, Carriers and Clips 


\subsection{Device Burn-In (Accelerated Aging)}

\subsubsection{Preparation of Devices at Static-Safe Work Station}

Preparation of device burn-in begins by placing the desired devices on a grounded work station while wearing a wrist strap. Whenever devices are handled at the grounded work station, at least one ionized air blower is directed toward the devices. Devices should be serially numbered, if not, serial numbers are assigned to them using a soft lead pencil. Each device identification number is entered in numerical order on a "serial number" sheet (used mainly during device testing).

\subsubsection{Preparation of Burn-In Boards}

Making sure that correct boards are selected for the specific temperature, the proper burn-in boards are placed on the work station and checked for correct operation. A high resistance may exist between open socket pins on a burn-in board if the sockets contain a material such as Torlon. A high resistance such as this (usually in megohms) that produces a voltage on open pins could cause damage to the device, thus creating a false failure. Because of the hydroscopic nature of Torlon, this high resistance must be eliminated by baking the board at $300^{\circ} \mathrm{F}$ for 24 hours with no voltage bias applied. Each time the sockets are exposed to normal temperature and humidity for 
periods in excess of 48 hours, the above procedure must be performed before the sockets are reintroduced to burn-in. After a successful completion of the board check by use of a VOM, devices are installed in the sockets and the location of each device is recorded by serial number on a "location sheet." The location sheet aids in placing devices in the same position on the boards for all cycles of aging. This is done so that if a "freak" failure should occur the possibility it was caused by a defective socket can be evaluated. A shorted edge connector is installed on the connector end of each board until the board is inserted into an oven if the floor between the work station and oven is not equipped with a static draining floor mat.

\subsubsection{Load Card(s)}

As noted in Figure 3, each burn-in board has a corresponding "load card" needed for supplying voltage bias and timing to the devices. Construction of the load card is usually accomplished in the MEL. Figures $5 a-c$ show the burn-in oven systems with loaded burn-in boards and load cards.

\subsubsection{Oven Capability and Device Burn-In}

Figures $5 b$ and $5 c$ are photos of a front and back view of an oven system, respectively. Refer to these figures for relating the following description list: 
1. Pressure relief valve

2. Pressure gauge

3. Micrometer oven temperature control

4. Dial type oven temperature control

5. Temperature recorder chart

6. Oven temperature chamber

7. Loaded burn-in board inserted into oven

8. Burn-in board feed through connection to external load card

9. Feed through fingers (interface between interior and exterior of chamber)

10. Connection to wire-way for biasing

11. Connected load card supplying bias from wire-way to burn-in board

12. Blower for cooling power supplies

13. Seven-day temperature ON-OFF timer

14. Temperature meter

15. Percent power meter

16. ON-OFF switch

17. Temperature setting dial

18. Push to enable switch (all power supplies)

19. Push to disable switch (all power supplies)

20. Four power supply units

21. Dry nitrogen control and hose

22. Circuit breaker

The MEL's burn-in oven capabilities are as follows. Shown in the left half of Figure $5 a$ are two of four oven systems capable of $70^{\circ} \mathrm{C}$ to $315^{\circ} \mathrm{C}$, with electrical stress; the right half 


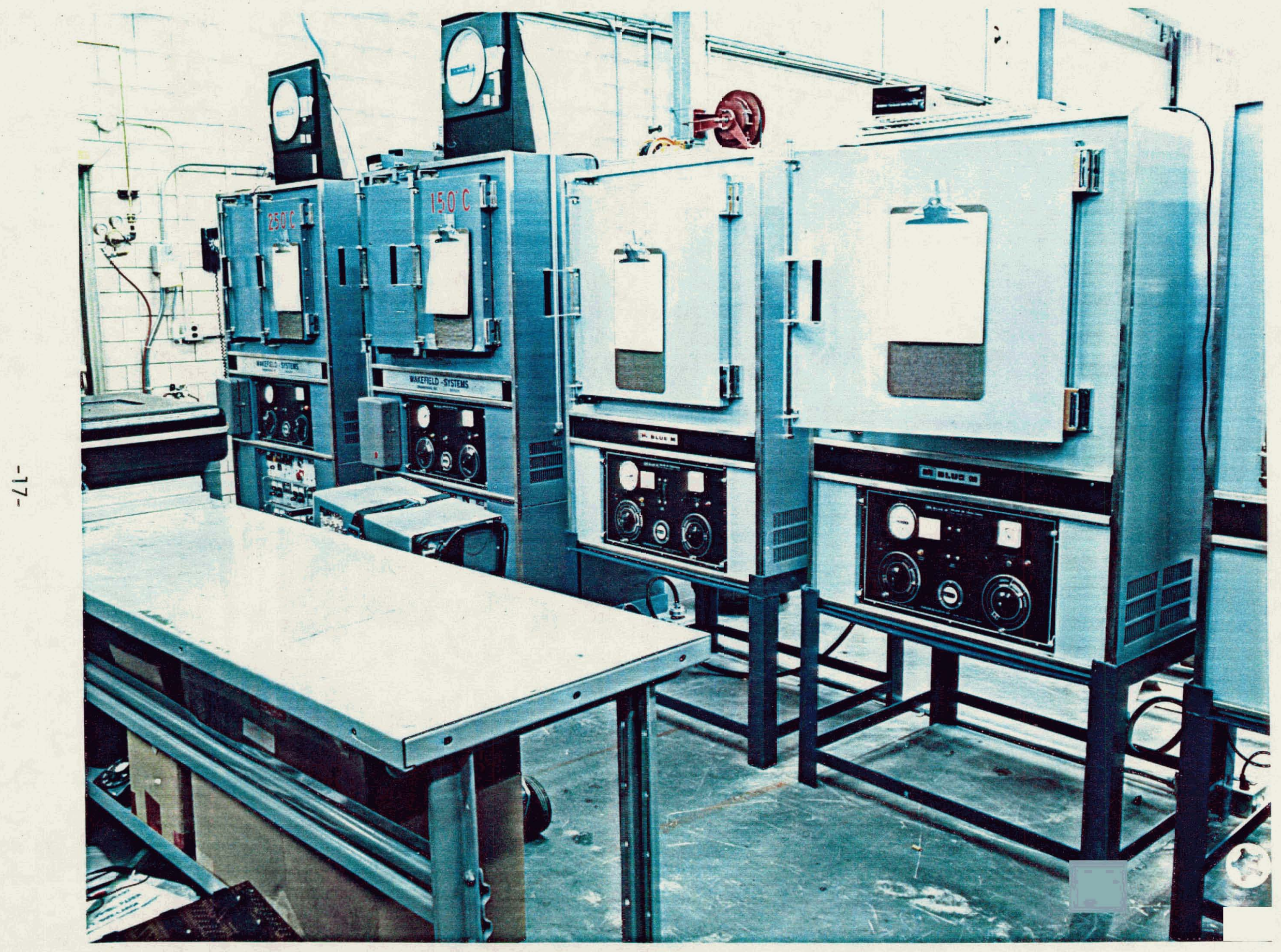

FIGURE 5a - Burn-in Oven Systems 


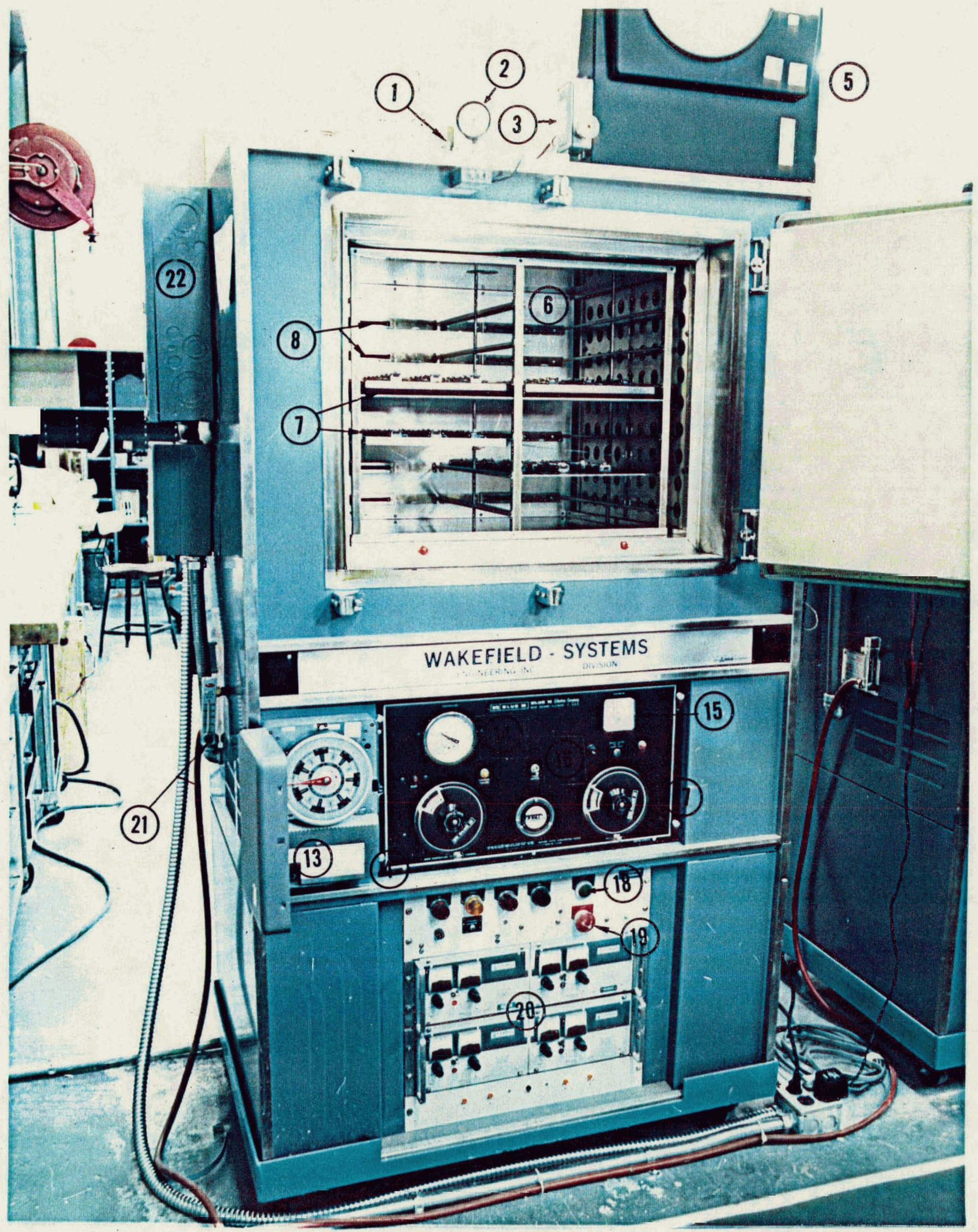

\section{FIGURE 5b - Front, Close-up View of an Oven System}




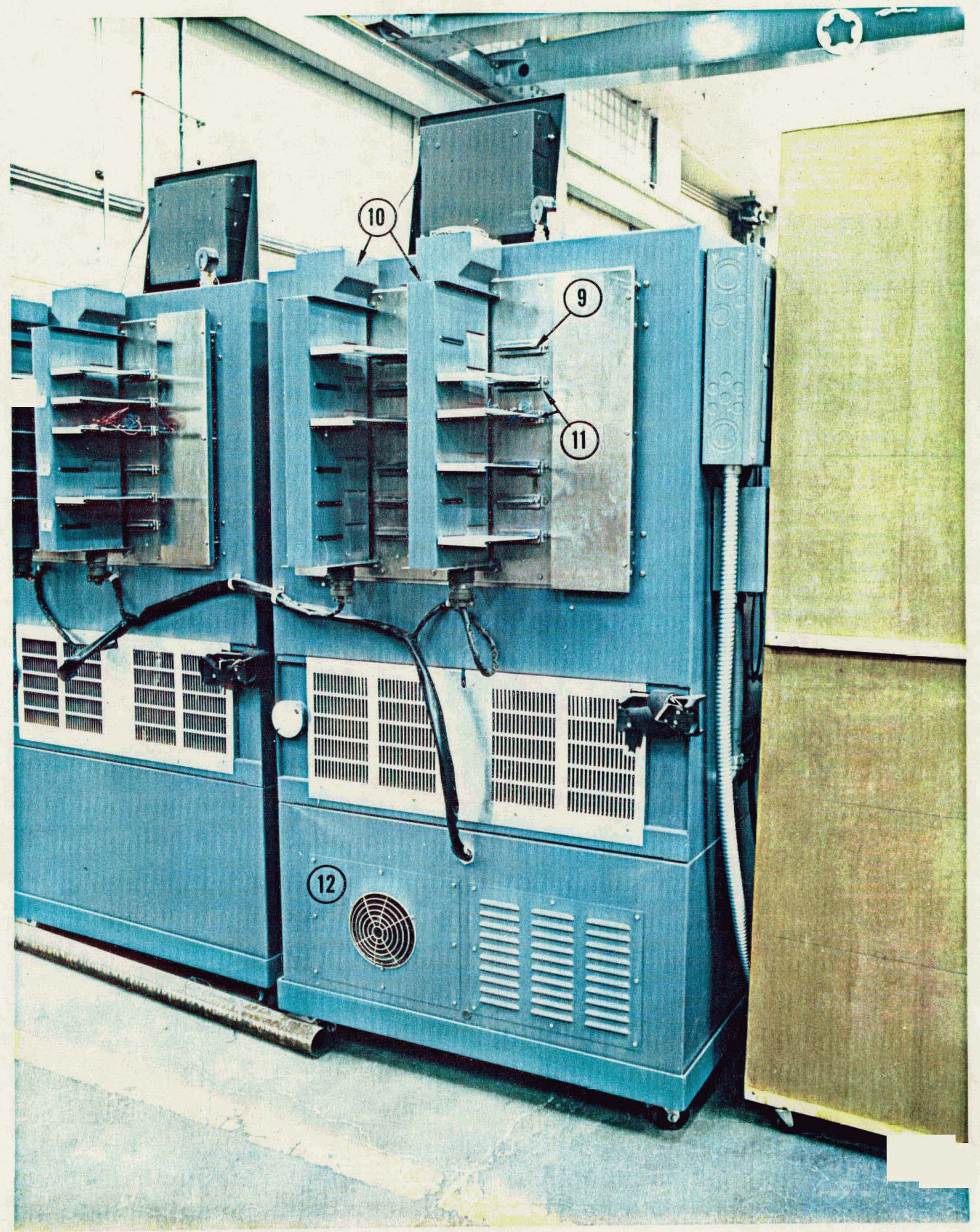

\section{FIGURE 5c - Back, Close-up View of an Oven System -19-}


of Figure $5 \mathrm{a}$ shows two of three other systems capable of $70^{\circ} \mathrm{C}$ to $200^{\circ} \mathrm{C}$, with no electrical stress; an eighth system (not shown) with three vertically stacked chambers is capable of temperature stress of $-55^{\circ} \mathrm{C}$ to $200^{\circ} \mathrm{C}$. The four oven systems with electrical bias capability allow burn-in boards (12 maximum per oven) with extended edge fingers to feed through the rear (back plane) of the oven chamber in order to engage with edge connectors outside the chamber. This is shown in Figures $5 \mathrm{~b}$ and $5 \mathrm{c}$. The corresponding load card is connected to the edge connector in back of the chamber. Each load card is connected to the wireway on the back of the oven which in turn is connected to the power supplies controlled at the front of the ovens. After loading burn-in boards and load cards oven, the temperature and bias controls are set, the oven door closed, and the oven power switch is switched to "ON." The desired stress is then applied to each board and aging begins. Dry nitrogen is supplied to the oven chamber to minimize corrosion on socket pins. An optional timer, shown on the front of the oven systems, is available for automatic control of UN and U.FF, cycles.

When the burn-in interval time has been reached, the oven's main power switch is turned "OFF" but the voltage bias is still applied. This is arranged because cool-down under bias is required, and device testing must be completed within an eight hour period after bias is removed. After cool-down, the dry 
nitrogen is turned off and before the voltage bias and burn-in board are removed from the oven, bias is checked on each board to assure it is the same as at start of aging.

\subsubsection{Unloading and Preparation for Device Testing}

After the boards are removed from the ovens, devices are removed from each board and prepared for transporting to the test area. The procedures used for loading boards are similar for unloading them. Shorted edge connectors are used during transport from the oven to the grounded work station, at least one ionized air blower is operating, and wrist straps are used while handling devices. Devices are unloaded by serial number or in order to be tested by referring to the serial number sheet or the burn-in board location sheet. Depending on the device type and on how the devices will be tested, they are. loaded into magazines, conductive foam, static bags, or static conductive pockets before loading into a conductive carrying case for transport to the test area. All of this apparatus is shown in Figure 6 with a full description as follows:

1. Magazines for flat pack devices.

2. Magazines for dual-in-line devices.

3. Magazines for leadless devices.

4. Conductive foam used mainly for dual-in-line devices.

5. Conductive pockets used mainly for leadless devices. 


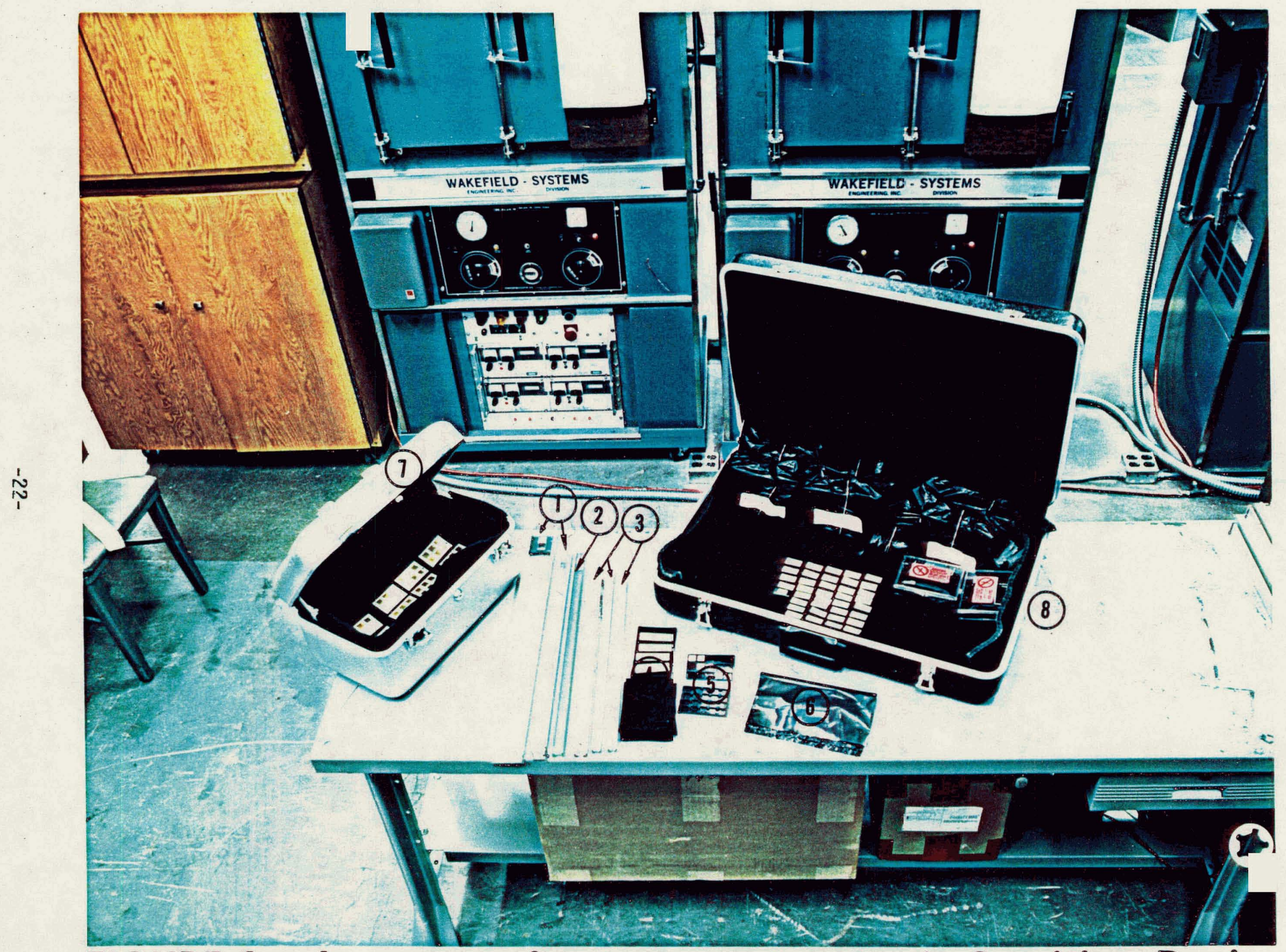

FIGURE 6 - Apparatus for Transporting Static Sensitive Devices 
6. Conductive bag used for all type devices.

7. Small conductive carrying case insulated with conductive foam used for safely transporting small amounts of static sensitive devices to distant areas.

8. Large conductive carrying case insulated with conductive foam used for safe transport of magazines and large numbers of static sensitive devices.

\section{SECTION 3}

\section{DEVICE TESTING}

\subsection{The Area and Test Equipment}

Device testing is performed on the Fairchild sentry VII tester. With the aid of the Sym-tek chamber, used for automatic device handling and temperature cycling, or the Temptronic, used for manual device handling, the Sentry VII is capable of testing at various temperatures, with $-55^{\circ} \mathrm{C}, 25^{\circ} \mathrm{C}$, and $125^{\circ} \mathrm{C}$ being the most typical. Temperature testing is performed to simulate stockpile environments.

The Sentry VII is fed test simuli through the "Test Head," which is independent of the sym-tek and Temptronic chambers. The test system is shown in Figures 7 and 8 with the following descriptions:

1. Temptronic temperature unit - supplies temperatures from $-55^{\circ} \mathrm{C}$ to $150^{\circ} \mathrm{C}$.

2. Temptronic temperature cage - confines temperature to device-under-test (DUT). 
3. Top of Temptronic used as a grounded work station.

4. Work station grounding card.

5. Grounded wrist strap for grounding personnel.

6. Test Head - supplies and receives biasing information to and from the DUT, and receives and sends instructions and data to the sentry VII.

7. Performance board, in place for direct connection to DUT inside sym-tek chamber.

8. DUT interface unit for use with chamber.

9. DUT interface unit for use when testing manually.

10. Sym-tek temperature chamber supplies $-55^{\circ} \mathrm{C}$ to $150^{\circ} \mathrm{C}$ temperatures.

11. Sym-tek device cycling unit.

12. Magazine insertion for loading devices into chamber.

13. Magazine - usually filled with devices prior to transporting to test area.

14. Ionized air blower - neutralizes static at the Test Head. An ionized air blower, not shown, is also placed at the Temptronic work station.

15. Dry nitrogen input to chamber. (The liquid nitrogen connection used for lowering temperature is located in back of the chamber.)

16. Dry nitrogen hose (red). Hose is also connected to the Temptronic.

17. Chamber temperature meter.

18. Wafer prober.

19. Sentry VII computer.

20. Magnetic tape drive - loads and receives information to and from the computer.

21. Video computer terminal - manually instructs computer through keyboard.

22. Teletype printer.

23. Chamber interface unit for leadless device. 


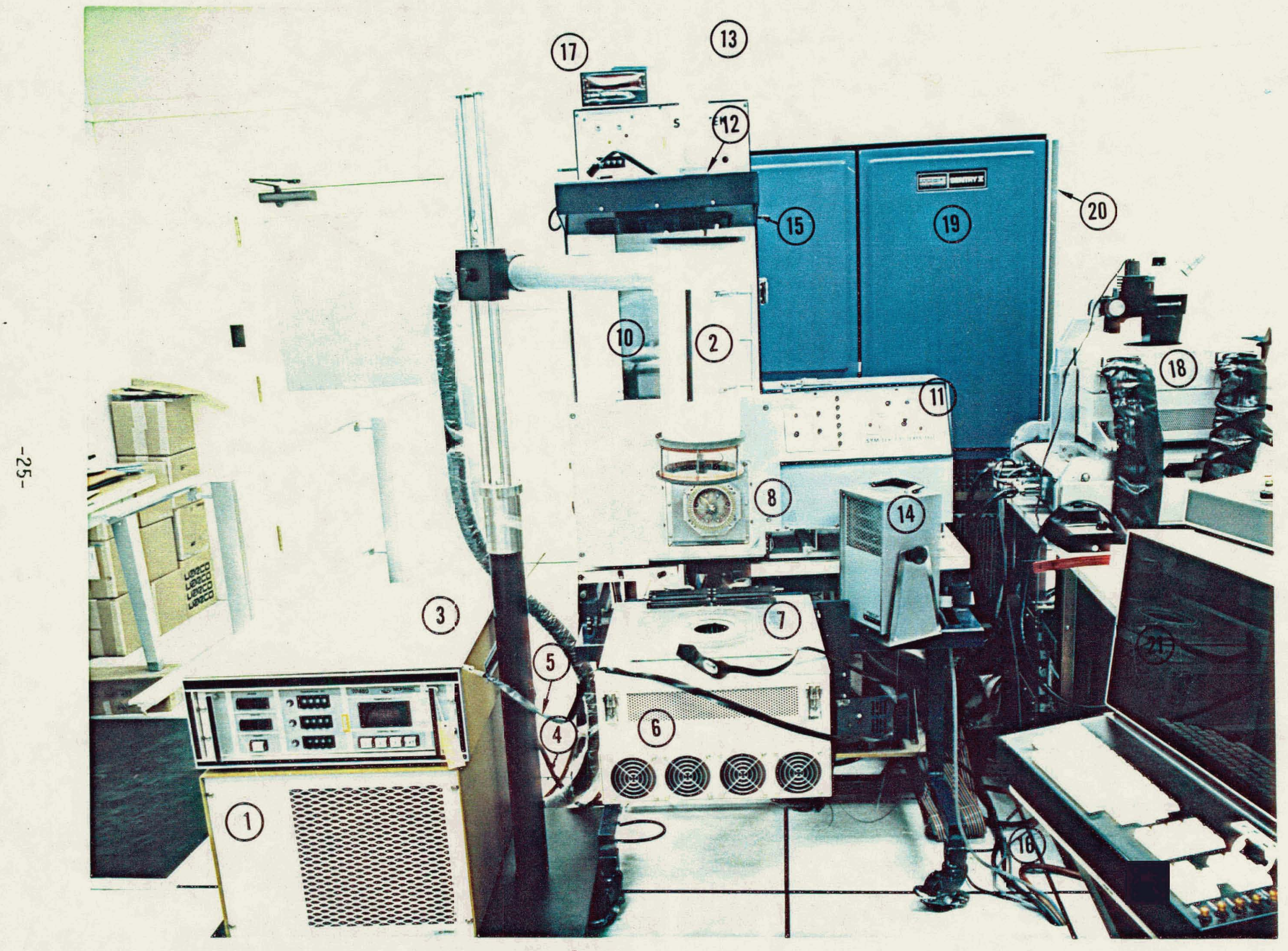

FIGURE 7 - Test Area and Equipment 


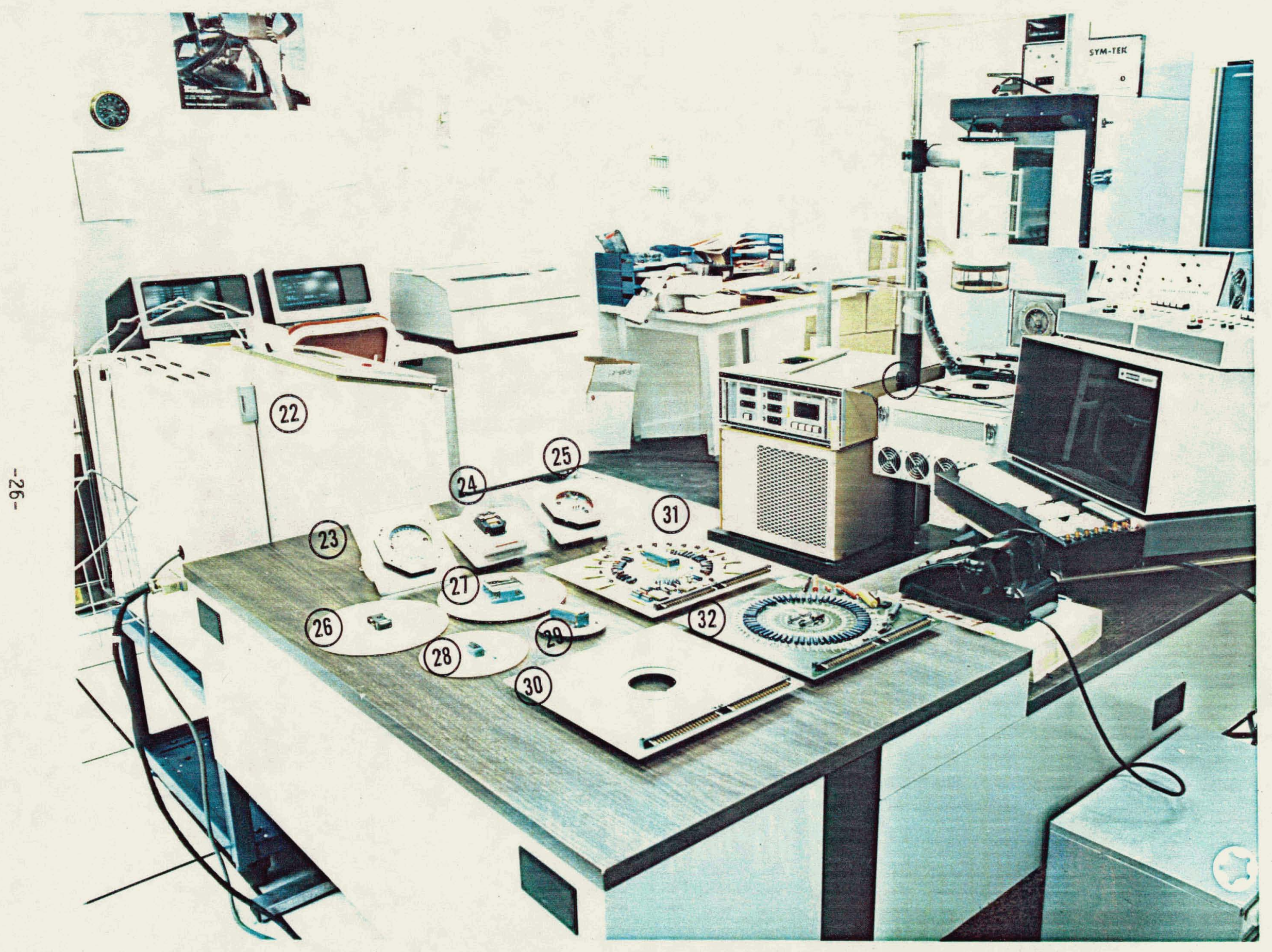

FIGURE 8 - Interface Units and Performance Boards 
24. Chamber interface unit for two-sided flat pack device (inside view).

25. Chamber interface unit for two-sided flat pack device (outside view).

26. Temptronic interface unit for leadless device.

27. Temptronic interface unit for 22- through 64-pin flat pack device.

28. Temptronic interface unit for 14- through 18-pin dual-in-line device.

29. Temptronic interface unit for 22- through 48-pin dual-in-line device.

30. General purpose performance board.

31. Microprocessor performance board.

32. Tester verification board (TVFY).

For manual testing, the Test Head is horizontally positioned and the Temptronic temperature cage is lowered over the DUT. Testing at temperatures other than ambient $\left(25^{\circ} \mathrm{C}\right)$ is very time consuming because each DUT must remain under the temperature cage for approximately two minutes until stabilized before testing can begin. For automatic device handling, the Test Head is positioned vertically against the sym-tek chamber with an interface unit between the Test Head and DUT. The interface unit is used for making DUT connection from inside to outside the chamber. The interface unit is attached to the front of the chamber. Usually each differently packaged device requires its own interface unit. One reason for manual testing as opposed to automatic handling and testing is that each diffèrently-packaged device does not have an interface unit for automatic device handing. 
Using the sym-tek chamber for temperature testing is preferable since all devices remaining in the chamber are sta-. bilized after the first two minutes. Thus, testing of the next device is performed immediately after the cycling-out of the previous one. Each differently packaged device has a performance board that must be attached to the Test Head before any testing can be performed. The performance board supplies voltage bias and timing to the DUT as instructed by the sentry VII and measured values are routed back to the sentry VII as data.

The Sentry VII instructs the Test Head to supply and receive bias information to and from the performance board and DUT. The operator, through loading the device program into the memory of the sentry VII, instructs the sentry VII. After program instructions are loaded into the computer at the tape drive, all further testing information is inputted at the video computer terminal. Data from the DUT can be retrieved at the video terminal, on magnetic tape at the tape drive, and/or at the teletype printer. Most data from devices used in weapon systems are put on magnetic tape and filed in the data center for future analysis.

\subsection{Running TVFY and Device Testing}

Upon reaching the test $1 \mathrm{ab}$, devices to be tested are placed on the surface of the Temptronic which is used as a small grounded work 
station. Before any testing is performed, the sentry VII is checked against a system "diagnostic" program. This is done by loading the Tester Verification (TVFY) tape into the system and through commands at the computer terminal, checking the testing operations with the load of the TVFY performance board attached to the Test Head. After an acceptable TVFY test; devices are tested either manually or by automatic handling by use of the sym-tek chamber. All device passfail information is recorded on the serial number sheet for that device. Liquid nitrogen is used for lowering temperature in the chamber and dry nitrogen is blown on the tester sym-tek interface unit to prevent frost on terminals.

\subsection{Data Acquisition}

When the MEL testing first began, testing was performed at a low, high and ambient temperature. Later it was noticed that on the average when a device failed at one temperature, failure occurred at the other two temperatures shortly afterward. Now, with the exception of pre-burn-in testing, devices are tested only at the ambient temperature until a functional fail occurs. After that, testing is performed at all three temperatures. When testing is complete, the data tape is taken to the data center, data from the line printer is filed in the MEL office, and devices are transported back to the burn-in lab. After failures have been removed, the device aging test cycle is continued until $16 \%$ to $50 \%$ total failure occurs. Devices are loaded per the burn-in board form prepared 
earlier. A flow diagram of the aging test cycle and treatment of failures is shown in Figure 9.

\section{SECTION 4 \\ THE USE OF FAILURES}

Additional data at the line printer is taken on failed devices. The data and failed devices are given to the failure analysis group where devices are analyzed to determine cause of failure. As an aid to failure analysis, most failed devices go through bake-out" (storing at elevated temperature with no voltage bias) and a test cycle prescribed by the failure analysis group. This, is shown in Figure 9. Through the cycle, some of the failed devices may recover and tend to perform as a good device. This condition is helpful in determining mode of failure.

All failures obtained through the aging study are used as data points for predicting life expectancy of that particular type device. An ideal plot was shown in Part III of Figure 1.

\section{SECTION 5}

\section{SUMMARY AND CONCLUSIONS}

In accelerated aging, specific, controlled stresses are applied to the device to accelerate time-to-failure. Data is used in mathematical models to estimate 1 ife in actual use. The stresses used for this technology are temperature and voltage. 

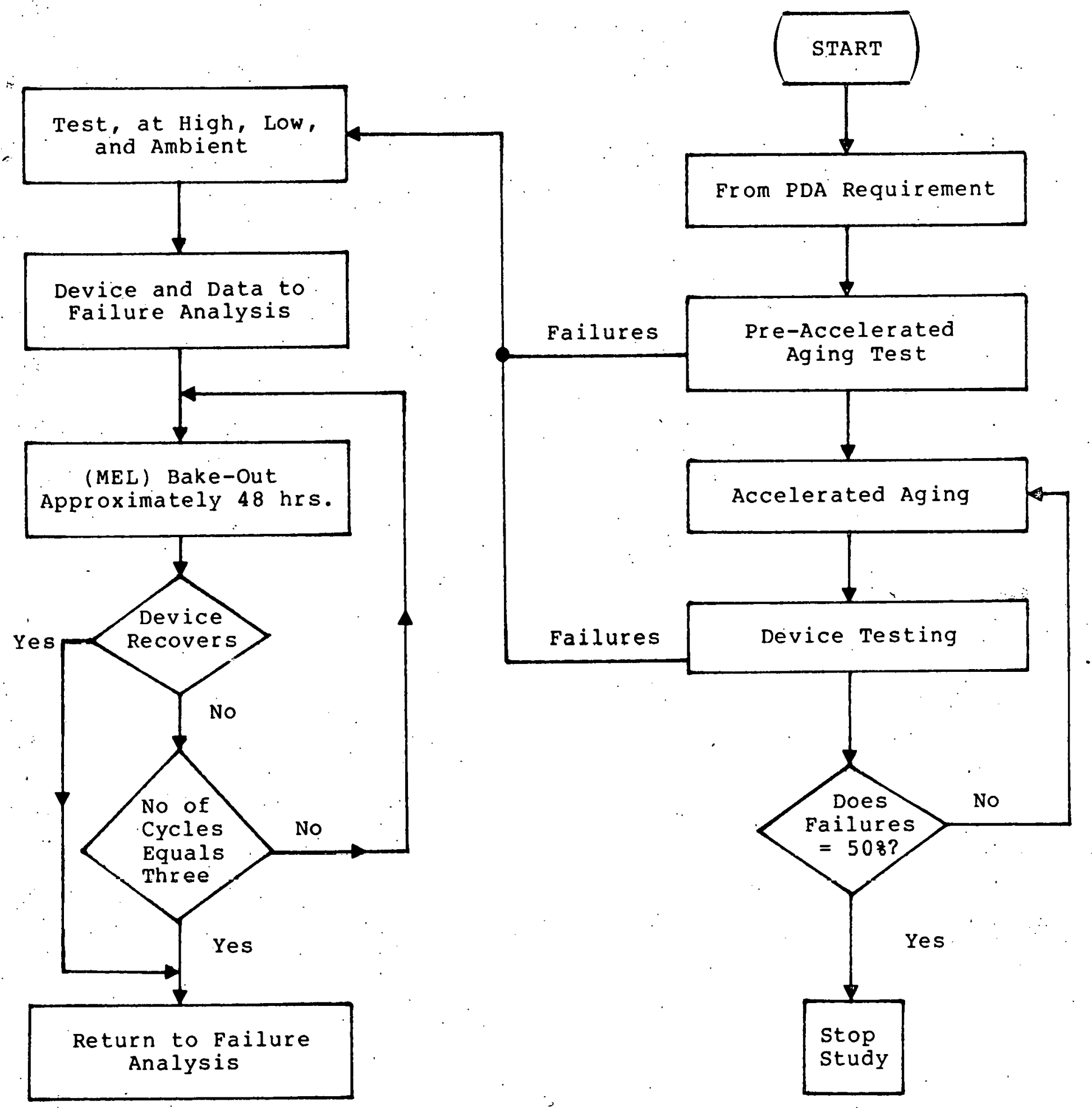

Figure 9 - Flow Diagram of Accelerated Aging
Burn-In, Test and Failure Analysis Cycle 
The devices are stored at temperatures with or without voltage applied (steady-state or cyclical) and periodically tested until at least 50 percent failures are encountered. Since most current technologies use "epoxy-die-attachment," aging temperatures must be under $200^{\circ} \mathrm{C}$. This delays device failure, and a 168 failure level is used when this extrapolation is considered valid. Statistical analysis is performed on the resultant data to predict reliability with time.

All devices, after functional failure has occurred, are given to the failure analysis group for failure evaluations. In order to improve reliability predictions, failure analysis is most concerned with the separation of freak and main 1 ife mechanisms. Through these evaluations, higher reliability and longer device 1 ife have become a milestone of the future. 


\section{SECTION 6}

\section{REFERENCES}

1. Morton Stitch, Gordon M. Johnson, Bruce P. Kirk, Joseph B. Brauer, "Microcircuit Accelerated Testing Using High Temperature Operation Tests," IEEE Transactions of Reliability, Vol. R-24; No. 4, October 1975, pp. 238-240.

2. D. S. Peck, O. D. Trapp, "Accelerated Testing Handbook," Technology. Associates, 1978 .

3. "Test Methods and Procedures for Microelectronics," MIL-STD$883 \mathrm{~B}$.

4. J. M. Soden, "PDA Criteria for IC Burn-in," report written to W. R. Dawes, July 1979, pp. 9, 13-14. 
Distribution:

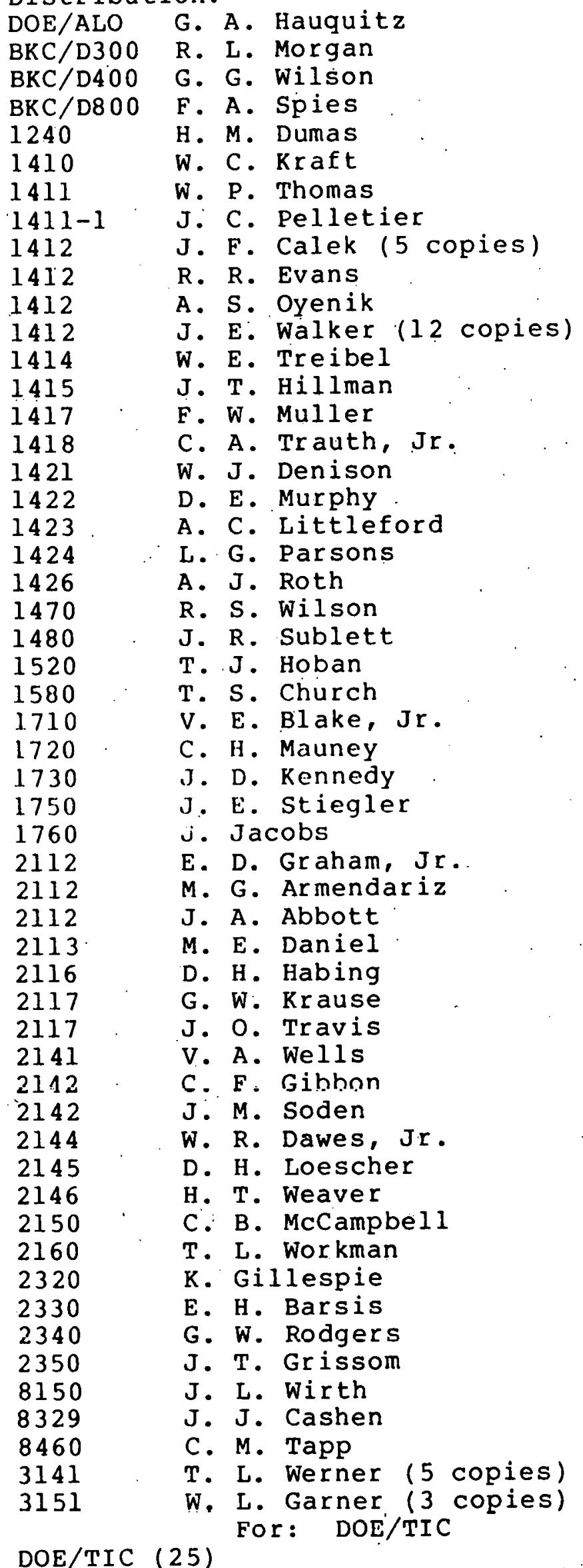

(R. P. Campbell, 3154-3) 
